\title{
A review on the role of functional limitations on evacuation performance using the International Classification of Functioning, Disability and Health
}

\author{
Olivera Bukvic, Department of Civil Engineering and Geodesy, University of \\ Novi Sad, Novi Sad, Serbia \\ Gunilla Carlsson (D), Giedre Gefenaite (D), Björn Slaug (D) and \\ Steven M. Schmidt (D), Department of Health Sciences, Lund University, \\ Lund, Sweden
}

Enrico Ronchi (iD*, Department of Fire Safety Engineering, Lund University, Lund, Sweden

Received: 9 April 2020/Accepted: 13 August 2020

\begin{abstract}
This scoping review addresses the role of functional limitations on evacuation performance of adults in public buildings. Although this topic has been addressed in evacuation research, no linkage is currently available between functional limitations, the predominant activities affected by them and evacuation performance. This review strives to open a debate on the need to classify the impact of disability in terms of functional limitations on evacuation performance according to methods adopted in health science. This paper reviews literature concerning evacuation from public buildings with adults aged $\geq 60$ years and/or adults aged $\geq 18$ years with functional limitations. The International Classification of Functioning, Disability and Health has been used to identify predominant activities during an evacuation and to perform a structured classification at different levels of resolution to address selfevacuation possibilities. Results of the review are presented in a tabular form linking predominant activities in terms of the International Classification of Functioning, Disability and Health and six categories of functional limitations with the engineering evacuation time-line. The suggested classification can facilitate the assessment of the evacuation-related issues in buildings in relation to the population under consideration. The main research gaps identified include the lack of studies concerning the impact of cognitive limitations on egress, and the need to add the temporal dimension to the methods adopted in accessibility research to allow for their use in the egress field.
\end{abstract}

Keywords: Ageing, Egress, Disability, Fire safety, ICF, Impairments

\footnotetext{
* Correspondence should be addressed to: Enrico Ronchi, E-mail: enrico.ronchi@brand.lth.se
} 


\section{Introduction}

The ability of people to egress in case of an emergency scenario is a well-established scientific field, with several applications, including performance-based design of fire evacuation [41] and crowd management. This is often called evacuation, while the term egress refers to the movement out of a building/infrastructure in normal conditions.

The ageing process might worsen the ability of an individual to perform selfevacuation and demonstrate the importance of taking specific needs into consideration when functional capacity decreases and disability increases [69]. This is confirmed by the trends in fire-related deaths highlighting the vulnerability of older people, i.e., they have been shown to be at higher risk of dying in fire accidents $[15,30]$. For example, Boyce states that chronic conditions linked to ageing such as cardiovascular disease, stroke, diabetes, cancer, arthritis and osteoporosis, along with obesity, could prevent people from performing evacuation activities successfully [8]. Given the projected worldwide demographics with an increasing ageing population and associated chronic conditions that cause disability, this issue will most likely become even more relevant in the future [71].

Despite the efforts from a regulatory perspective [11, 31, 62] made over the years to address the needs of people with different levels of functional capacity, several issues still remain unsolved. In fact, limited guidance is available on the specific needs of people with disabilities in case of evacuation [13]. Evacuation research in fire safety engineering refers often in general terms to the needs of "people with disabilities" [4], instead of addressing a variety of functional limitations. The term functional limitations used in this paper is commonly adopted in the health science domain and defined as restrictions in performing fundamental physical and mental actions used in daily life [72]. A classification of functional limitations can thus be instrumental to distinguish the issues people may experience in performing basic activities. Previous research efforts in evacuation have focused on quantifying the ability of people with mobility limitations to perform evacuation tasks, e.g., see a recent compilation of data available in [19]. These data provide useful inputs for evacuation models and allow inclusion of quantitative variables of evacuation performance [23]. Nevertheless, a further step is needed to increase the knowledge about the various needs of people with different functional limitations in evacuation activities and subsequent evacuation performance. Detailed linkage between classified functional limitations and the predominant activities affected by them and evacuation performance has not been performed. In contrast, detailed classifications are used in the field of accessibility [67].

The idea behind this work is therefore to take advantage of existing research in the field of health sciences and accessibility research [67] and adopt a well-established classification, which is new in the field of fire safety, to assess the role of functional limitations on evacuation performance. To the authors' knowledge, this approach has never been used in evacuation studies. In addition to using the concept of functional limitations from the Disablement Process [72], the International Classification of Functioning, Disabilities and Health-ICF (World Health 
Organization [75]) provides a well-defined universal terminology. ICF describes disability as a wider term for impairments, activity limitations and participation restrictions which represent "problems an individual may experience in involvement in life situations" [75]. Impairment is defined as "loss or abnormality in body structure or physiological function (including mental functions)" [75]. The term activity means execution of a task or an action by an individual. Activity limitations are "difficulties an individual may have in executing activities; an activity limitation may range from a slight to a severe deviation in terms of quality or quantity in executing the activity in a manner or to the extent that is expected of people without the health condition" [75]. That is, for an individual to exit a building or to reach a safe place, a series of evacuation activities is needed, e.g. locating exit signs and finding architectural elements.

To integrate functional limitations and the ICF into the fire safety domain, an interdisciplinary research project has been initiated by a team of experts in disciplines such as fire safety engineering, gerontology, epidemiology, occupational therapy, psychology and public health. A key goal of the project is to provide a detailed classification of the links between evacuation activities, functional limitations and predominant activities in light of ICF. In this context, the term egressibility is used to represent the accessibility of means of evacuation. This will help improve the design of safe evacuation for all people, identify research gaps and inform regulatory work in fire safety.

\section{Method}

The articles for this scoping review were primarily retrieved from the Science Direct and Scopus databases. The search was based on a set of keywords: "egress", "evacuation", "people with disabilities", "old people", "impaired", "public buildings", "fire safety" resulting in a total of 6780 Science Direct and 427 Scopus papers. In addition, 60 papers were included based on suggestions provided by experts in the relevant field and by screening the references of the papers included. The research work was conducted in the period from February 2019 to August 2019. Most papers were retrieved in the first two months and the search was regularly updated up to the end of the study period. For papers to be included, they had to address evacuation from public buildings with adults aged $\geq$ 60 years and/or adults aged $\geq 18$ years with functional limitations. The choice of investigating public buildings was made to focus on buildings which are of common interest, thus possibly representing a starting point for future regulatory developments. Given the scope of the review, papers were excluded if they only focused on policy, only used/presented evacuation modelling methods, or were done in residential or nursing homes as the main focus in this work was on buildings where self-evacuation takes place. For details, see the flowchart in Fig. 1.

Information about the evacuation process of people with disabilities was extracted at a behavioural level. This included reviewing evacuation activities performed depending on functional limitations and identifying the links between the situations and the activities as classified by ICF. From the selected literature, the speci- 


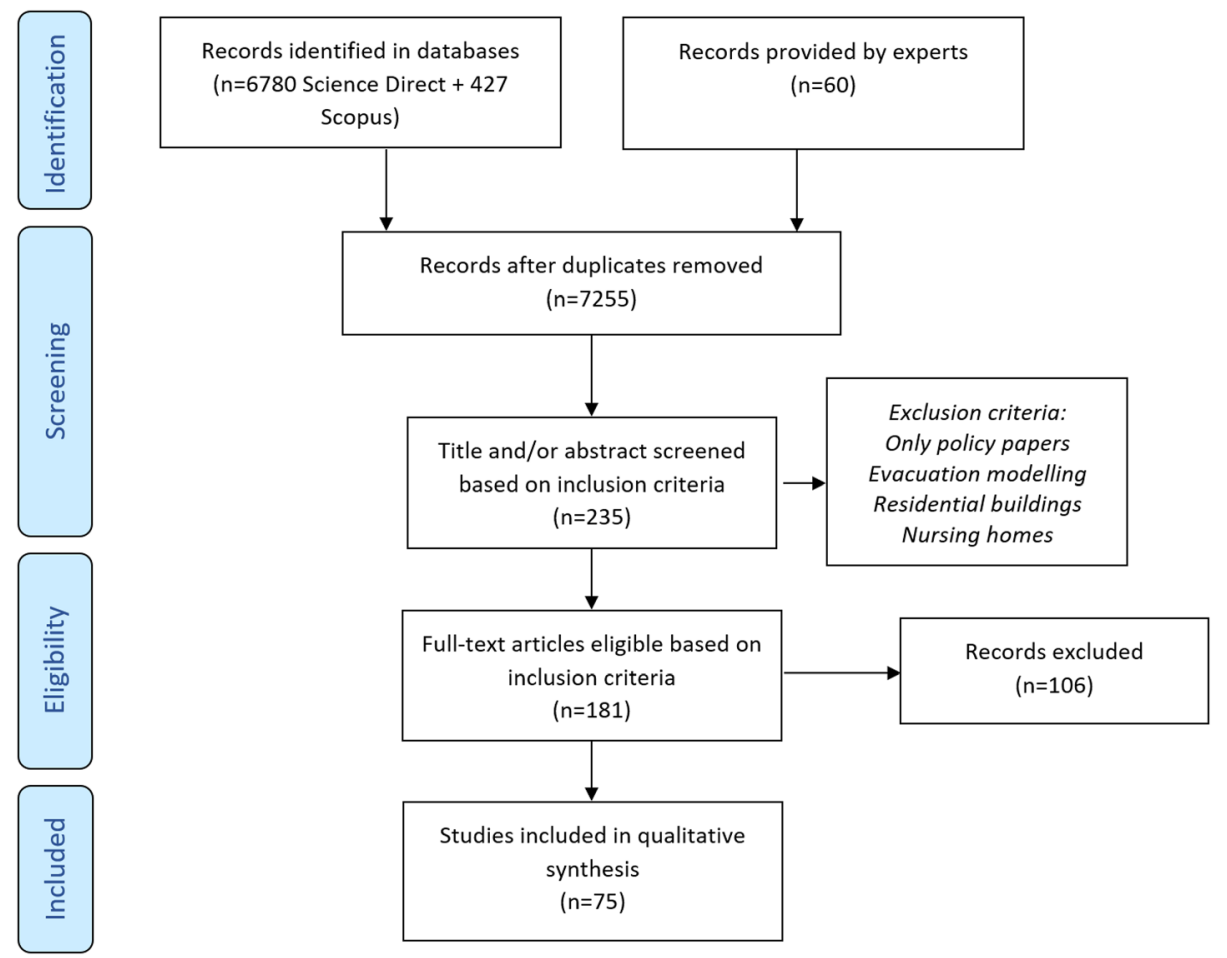

\section{Figure 1. Flow chart of the approach adopted for the literature review.}

fic evacuation activity and its relation to specific functional limitation were extracted. This means that the activities and functional limitations were not simply analysed at the basic detail level (e.g. evacuation activity-walking; functional limitation-mobility impairment) or in general. The extracted data were instead presented considering the activities potentially hard to perform and their relation to each specific functional limitation (e.g. activities such as moving on horizontal, moving on incline, opening doors; functional limitation-separating mobility impairment and upper extremities impairment). The exact types of functional limitations and their effects on evacuation performance found in each paper were then categorized by the first author. In case of uncertainty, a group discussion with the co-authors was initiated to consolidate the process. This categorization was performed along with the identification of functional limitations relevant for safe evacuation. To add an environmental dimension to this categorization, potential barriers for populations with disabilities were extracted from the body of literature.

Based on ICF, the list of activities that could be challenging for populations with disabilities during evacuation - in relation to the associated barriers-were identified. Disabilities were classified according to the type of functional limitation 


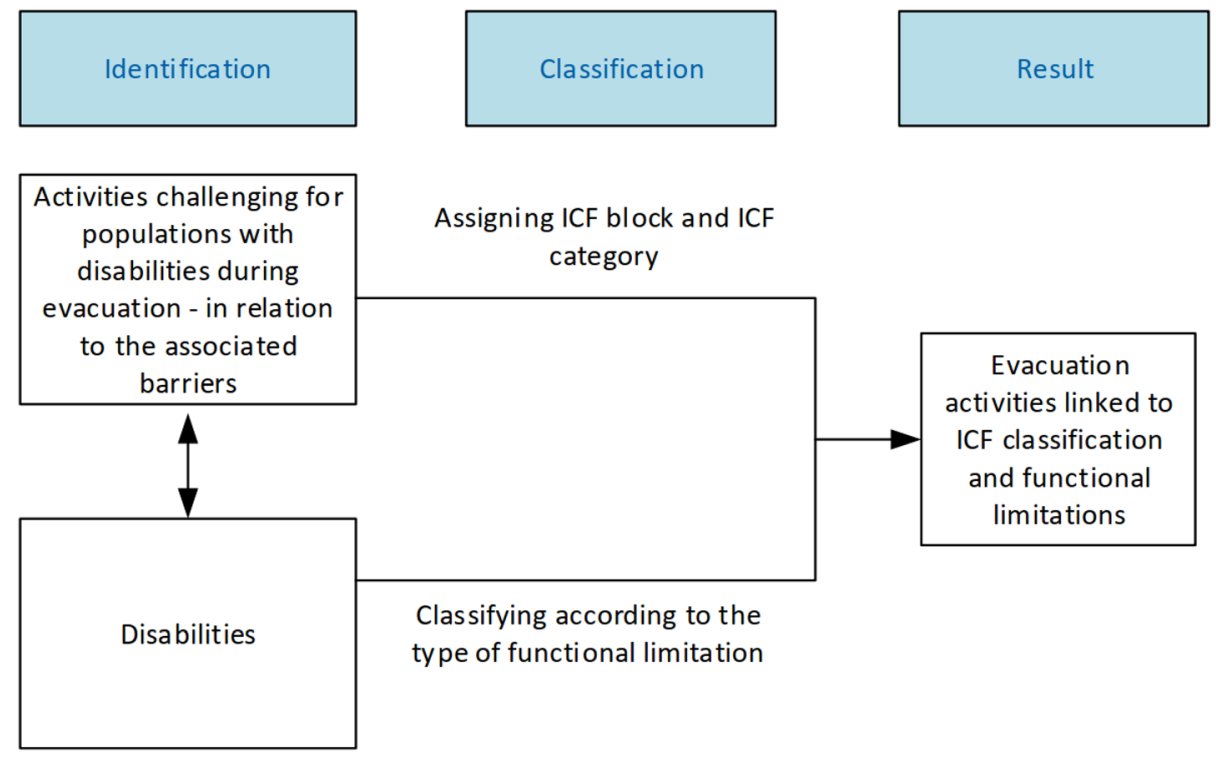

Figure 2. Flowchart of the linking process of the evacuation
activities, ICF classification and functional impairments.

(e.g., cognitive, visual, mobility, etc.). Links between ICF activities and participation (i.e. ICF classification components [75] and issues affecting evacuation performance were identified. In the ICF, activities and participation are divided into the chapters (e.g., Learning and applying knowledge, Communication, Mobility, etc.). Chapters are subdivided into "blocks", as a convenience to the user (e.g. Purposeful sensory experiences, Applying knowledge, Communicating-receiving, Communicating-producing, Changing and maintaining body position, Carrying, moving and handling objects, etc.).Within each chapter, under the ICF blocks there are two, three or four level "categories", representing the more detailed level of description of activity or participation (e.g. Watching, Listening, Solving problems, Making decisions, Conversation, Changing basic body position, Transferring oneself, etc.) [75]. In the present paper, a two-level classification was adopted to simplify the analysis and allow an easier evaluation of the linkage between ICF and evacuation activities. An ICF block and an ICF category were assigned to every evacuation activity found in the body of literature as potentially affected by functional limitations. This process is presented in Fig. 2. ICF does not classify people but rather describes the situation of each person within an array of healthrelated domains [75]. Since ICF refers to normal conditions (i.e. not during a fire or other catastrophic events), specific characteristics of fire emergencies and evacuation were taken into consideration. The outcome is the linkage of evacuation activities to ICF activities and the type of functional limitation affected. 
To provide a temporal dimension to the analysis, the engineering evacuation time-line [56] was used to build a connection between the situations people may face during an emergency and their actual functional limitations. Every evacuation activity was therefore linked with three different evacuation phases [62]. (1) The alarm time (A) is intended as the time from detection of the threat to the general alarm going off. (2) The pre-evacuation time (P) consists of the sum of the recognition and response times. The recognition time is how long it takes for people to become aware of the alarm and start to respond. The response time starts after occupants become aware of the alarm and start responding and ends when they make a purposive movement towards a safe place. (3) The travel time (T), therefore starts when a person has made up their mind and starts their purposive movement until they reach a safe place [62]. It should be noted that alternative terminology of the phases of the evacuation time-lines are available in the literature (e.g. the term pre-movement is often used instead of pre-evacuation or the term movement time is used instead of travel time [56]).

The link between the activities to be performed and the given evacuation phase is deemed to add a time dimension to the problem, which is a key factor for safe evacuation. In other words, it highlights not only the fact that people may or not be able to perform a task based on their functional limitation (as is currently done in accessibility research), but also how long that task would need to be performed; this implicitly considers the extent to which a functional limitation can affect evacuation performance.

\section{Results}

The selection of articles was classified in three groups: case studies, evacuation trials and egressibility studies. Papers containing information about past evacuation events and inquiries focusing on causes of fires and fatalities in context of older adults or people with disabilities were categorized as case studies. Statistical data such as percentage of older people and people with disabilities among the total number of victims/survivals and the percentage of fires caused by them was extracted along with data on prevalence of impairments and disorders. Papers with data about human behaviour, walking speeds, testing and assessment of evacuation performance activities of target groups (through experiments and/or interviews on their experience) were classified as evacuation trials. Egressibility studies refer to papers addressing how accessible the means of egress are for older people and/or people with disabilities. This includes information about the use of assistive devices for movement and way-finding aids for populations with mobility limitations. The final number of resulting papers was 75 of which 25 were eventually used to perform the link between ICF and evacuation activities. Those included 11 qualitative studies, 8 quantitative studies and 6 studies that used both qualitative and quantitative methods.

The identified evacuation activities and their links to the phases of the evacuation time-lines are provided in Table 1. A more detailed analysis of the information extracted from the papers is presented in a spreadsheet as supplementary 


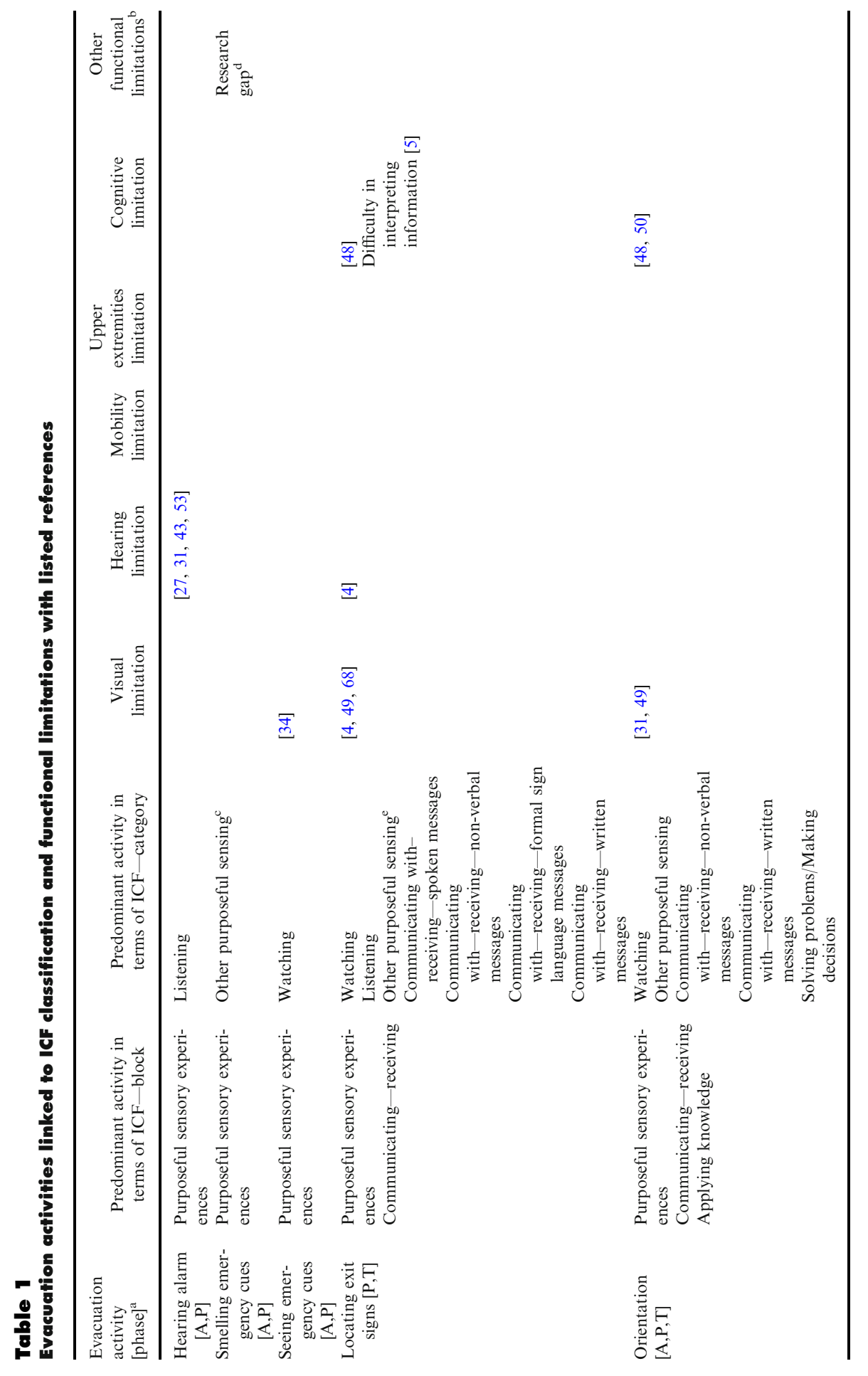




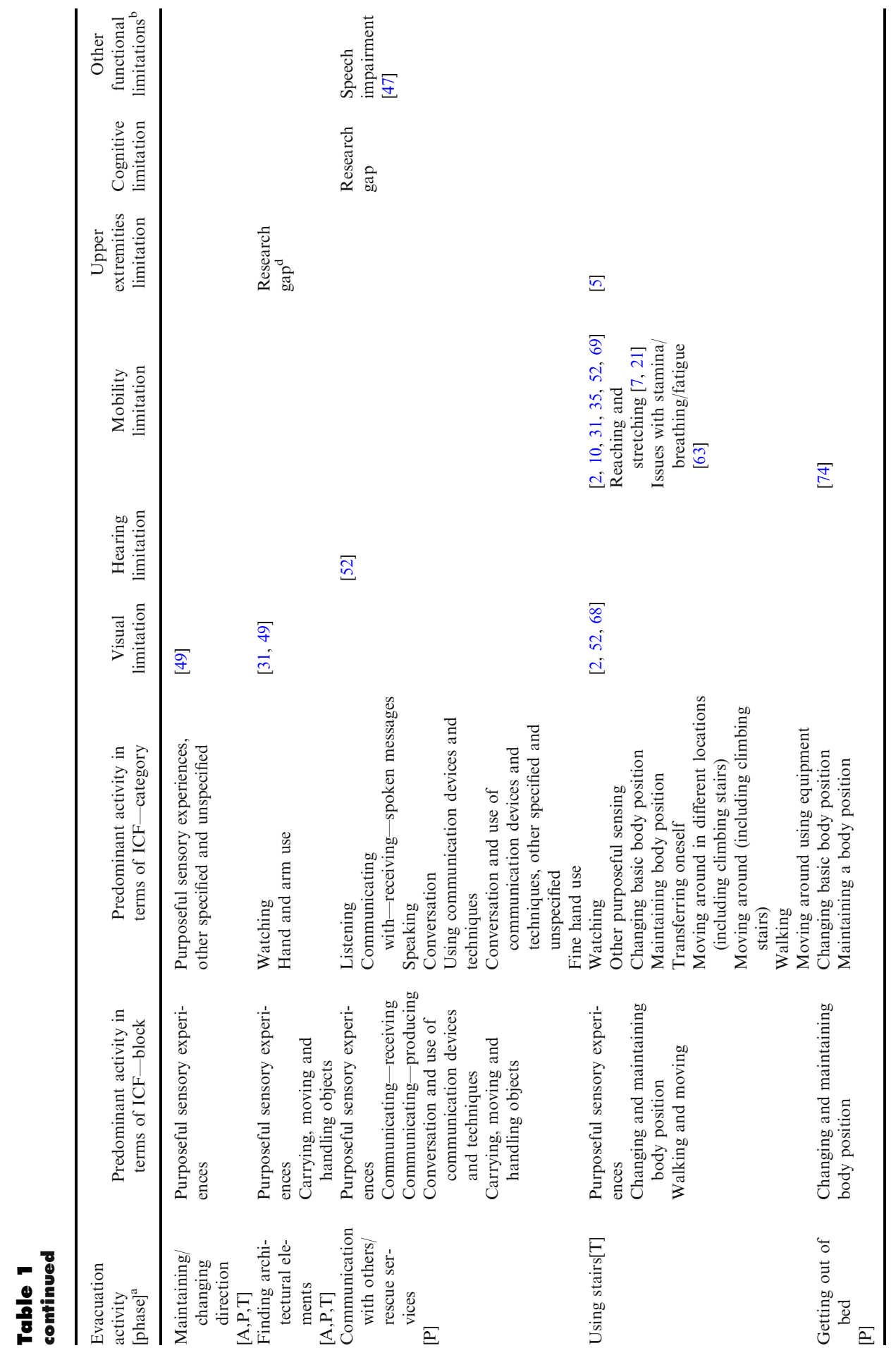




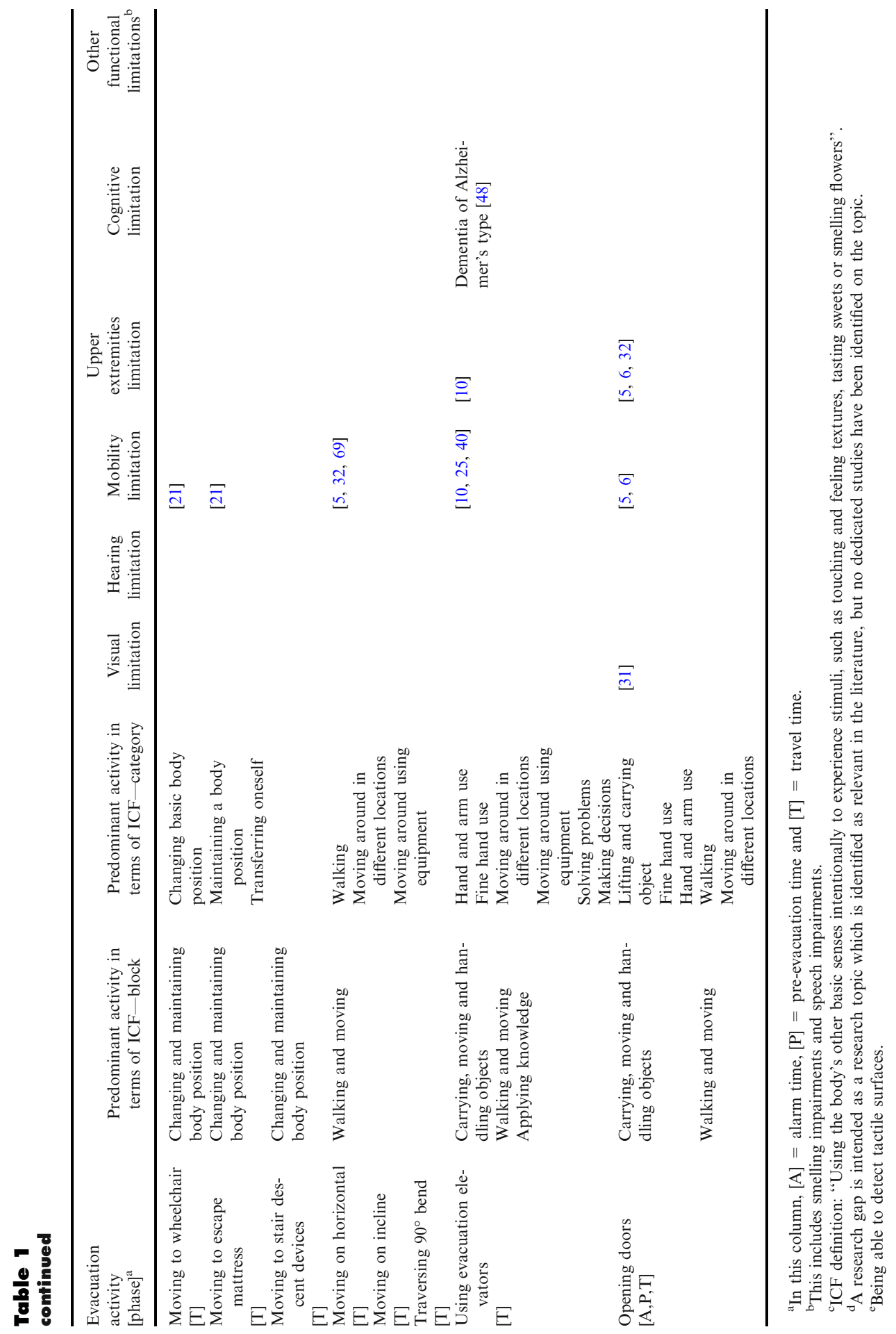


information. Due to the complexity and variability in the emergency scenarios, evacuation activities were sometimes placed in more than one evacuation phase.

The evacuation activities Hearing alarm, Smelling emergency cues and Seeing emergency cues are assigned both to alarm time and pre-evacuation time. An alarm can be heard as soon as it starts, and emergency cues (e.g. including seeing and smelling) maybe sensed from the moment of ignition, which qualifies these activities as alarm time (e.g. seeing/smelling smoke). On the other hand, these activities are also categorized as pre-evacuation phase since they can represent the delay time, information gathering or any activity before purposive evacuation movement [62]. Locating exit signs belongs to pre-evacuation time as it is defined as information gathering. This activity can be performed while following the evacuation path and therefore belongs to travel time as well. The activities Orientation, Maintaining/changing direction and Finding architectural elements are assigned to all three evacuation phases. Although they mostly refer to movement while being performed, this movement can occur also while gathering information (during alarm or pre-evacuation) or moving along the evacuation path (travel time). Getting out of bed is an activity mostly associated with trying to gather more information and is here classified within the pre-evacuation phase. The evacuation activity Opening doors can be performed in every stage of evacuation, and it can be linked with different purposes. Therefore, it is assumed to belong to all three evacuation phases. All remaining activities in the table are assigned to travel time. They all refer to movement for the means of egress.

The classification of visual, hearing, mobility, upper extremities or cognitive limitation demonstrated the complexity of the evacuation process. For example, the separation of upper extremity limitations from mobility limitations is used to distinguish the ability to move in general from the ability to handle objects with hands; e.g., a person may be able to move in general but may experience difficulties in grasping the door knob or pushing the door itself. Other functional limitations refer to impairments related to speech and smelling.

The activity Hearing alarm refers to ICF block Purposeful sensory experience, category listening. Several issues have been identified in the literature concerning the audibility of sound alarms. People may have problems hearing specific ranges of the sound spectrum, e.g., older people may have issues hearing $>2000 \mathrm{~Hz}$ frequencies [53]. For instance smoke alarms may not be suited for people with moderate to severe hearing impairment given the fact that they are generally emitting signals in the mid to high frequencies [27, 31, 43, 53]. These issues can have an impact on the human response in the alarm and pre-evacuation phase, i.e. delaying the response of people with hearing impairments.

The evacuation activity Smelling emergency cues belongs to ICF block Purposeful sensory experience. While the sense of smell is often reported in case studies [38] as clearly influencing human behaviour during the alarm and pre-evacuation phases [9], no research studies were found on how functional limitations linked to the sense of smell might affect evacuation performance.

The evacuation activity Seeing emergency cues also belongs to ICF block Purposeful sensory experience. It can represent any cue associated with the ability to 
see and become aware of danger during the alarm or pre-evacuation time (e.g., seeing smoke [34], fire, observing behaviour of other people, etc.).

Further, Locating exit signs also refers to ICF block Purposeful sensory experiences and Watching/listening/other purposeful sensing as categories. Issues associated with this activity depend on the degree of functional limitation (mild, moderate, severe or complete [75]). The use of exit signs designed to address the needs of populations with visually and hearing impairments is widely discussed in the literature, and different way-finding systems have been suggested [4, 49, 55, 67, 68]. Other purposeful sensing refers to the ability to feel tactile surfaces [75]. For instance, tactile surfaces can make information accessible for blind and visually impaired people. Their preferred evacuation path may be along walls and tactile surfaces [68].

An additional ICF block assigned to this activity is Communicating-receiving. Within this block, assigned categories are: Communicating with-receiving-spoken messages; Communicating with-receiving-nonverbal messages; Communicating with-receiving-formal sign language messages; Communicating with-receiving-written messages. While this activity can also refer to visual and hearing limitations, this category is associated with cognitive limitation here. Different cognitive disabilities can cause difficulties in reading, understanding and interpreting information [5, 67] and therefore affect the ability of people to locate exit signs during emergencies.

As concluded by Passini and Proulx [49] in a way-finding experiment with blind people, maintaining and changing the walking direction as well as spatial orientation for people with visual limitations is especially hard in public places where the background sound and noise can cover informative sounds and when occupants are not familiar with the particular space. In addition, congenitally blind people are not able to visually experience and memorize space [49], which makes performing evacuation activities even harder. In a case study on how people with disabilities perceive fire safety in historical buildings, people with visual impairments state the importance of a simple building design, so they can make a mental map of space and overcome issues with orientation [31]. Cognitive limitations linked to neurodegenerative disorders (e.g. Alzheimer's disease) affect the ability to memorize space, orientation and way-finding, thus making evacuation challenging for people with these types of cognitive impairments. Being able to make a decision or plan a series of activities in order to evacuate will depend on the severity of cognitive impairment as well as on space familiarity [48, 50]. In Table 1, the evacuation activities Orientation and Maintenance and changing direction are classified as ICF block Purposeful sensory experiences and categories Watching and Other purposeful sensing. In addition, Orientation is classified as Communicating-receiving ICF block as well as Communicating with-receiving-nonverbal messages and Communicating with-receiving - written messages categories. In this case, it refers to people with cognitive limitations experiencing difficulties in orientation and finding the exit without reference points or easily understandable and accessible information [48]. Furthermore, the ICF block Applying knowledge and the categories Solving problems and Making decisions relate to people with cognitive 
impairments and their limited ability to plan and perform an evacuation effectively.

Finding architectural elements is classified as ICF block Purposeful sensory experience with Watching as category and it refers firstly to difficulties for people with visual limitations to find the architectural elements that are a means of egress (i.e. staircase [31]) and make a decision where and how to move [49]. Secondly, this can refer to finding elements that can help occupants in orientation, which is often overlapping with the first interpretation.

Communication with rescue services in order to hear instructions to be rescued from a facility can be a relevant activity in case of a defend-in-place evacuation strategy, which is a commonly adopted strategy for impaired occupants [52, 58]. Five different blocks of predominant activities were assigned to it: Purposeful sensory experiences-for hearing impairment; Communicating-Receiving-hearing impairment and cognitive impairment; Communicating-producing-speaking impairment, Conversation and use of communication devices and techniques - speaking and cognitive impairment, Carrying, Moving and handling objects; upper extremities impairment in the case of need for using communication devices. In this context, the categories assigned are Listening/Communicating with-Receiving-Spoken messages/Speaking, Conversation/Using communication devices and techniques/Conversation and use of communication devices and techniques, Other specified and unspecified, and Fine hand use.

The evacuation activity Using stairs is a very common issue addressed in the literature for people with functional limitations. This includes both issues related to their own movement ability as well as issues for other occupants because they can represent a constraint on stair flows [2]. This activity is connected with visual, mobility and upper extremity limitations and several relevant ICF blocks and categories can be assigned to it (see Table 1). With regard to use of stairs, the ICF block Purposeful sensory experience includes two ICF categories: Watching and Other purposeful sensing. It is stated in several studies that people with visual impairments move slower on staircases due to their impairment, due to the complex shape or absence of tactile surfaces to help them navigate (see $[5,7,52,61$, 68]). The key evacuation issues could be the determination of each tread/end of stairs and transferring from one flight to another [68]. In a case study on the experiences of people with disabilities in Sweden considering the evacuation of historical buildings, people with visual and mobility impairments reported the issues of assessing the shape of stairs and the lack of handrails [31]. Support from handrails is indeed mentioned as one of the most important factors for visually and mobility impaired people while using stairs by Boyce et al. [7]. In this context, visual and mobility limitations combined with upper extremity limitations (Purposeful sensory experiences/Other purposeful sensing, i.e. grasping) could affect the ability of people to use stairs safely [7].

The effect of mobility limitations on the use of stairs is highly dependent on the type and degree of limitation. People with complete loss of ability to move need assistance to use stairs, and their evacuation depends on a rescue team or help from other occupants and/or descending devices [10, 26, 28, 35-37, 42]. Using stairs in the context of mobility limitations is defined in ICF as the block 
Changing and maintaining body position including categories as Changing basic body position/Maintaining body position/Transferring oneself and the ICF block Walking and moving including categories as Moving around different locations/ Moving around/Walking/Moving around using equipment. Mobility limitations are examined in more detail in the literature. Different health conditions may cause or significantly increase mobility limitations. Chronic conditions associated with ageing include cardiovascular diseases, diabetes, cancer, arthritis and osteoporosis, which can increase the prevalence of various disabilities [8]. Respiratory problems and obesity can be the main reasons for the need to rest during building evacuation in case evacuees need to travel longer distances [2, 18, 69, 70]. This issue is particularly associated with physical exertion [33, 63]. Obesity is common in developed countries, causing severe or complete loss of mobility [19, 69].

Getting out of bed is one of the main activities reported as causing falls in older populations [74]. Considering different degrees of mobility impairments, this can be significant for the pre-evacuation phase of occupants. The block of predominant activity assigned to this evacuation activity is Changing and maintaining body position. Changing basic body position and Maintaining body position are assigned as categories.

Evacuation activities Moving to wheelchair, Moving to escape mattress and Moving to stair descent devices (e.g. evacuation chair) refer to Changing and maintaining body position as block of predominant activity and Changing basic body position/Maintaining body position/Transferring oneself as categories. The performance of these activities is highly dependent on the assistance and preparation period, which differs from one helping device to another. For instance, the preparation times for the use of escape mattress, evacuation chairs or a wheelchair vary greatly [21].

Moving on horizontal, Moving on incline and Traversing $90^{\circ}$ bend were investigated in an experiment with participants with severe loss of mobility and wheelchair users, assisted and unassisted, mainly for the purpose of defining their movement speed [5, 32, 69]. These three activities refer to ICF block Walking and moving and ICF categories Walking/Moving around in different locations (i.e. incline-ramps, stairs) and Moving around using equipment (meaning helping devices).

Using evacuation elevators is often a means of evacuation for people with mobility limitations because it allows for independence while using a mobility device. Nevertheless, egressibility issues may arise for people with limitations in mobility or upper extremities if the elevator is in an enclosed lobby with heavy entrance doors [10]. For this reason, this activity is classified as a predominant activity block Carrying, moving and handling objects and Hand and arm use/Fine hand use as categories. Another block of predominant activity-Walking and moving-and categories Moving around in different locations; Moving around using equipment is also assigned to this activity since the elevators are a common means of egress for people with mobility impairments who are not able to descent the stairs independently [40]. Therefore, non-accessible evacuation elevators would represent a constraint [24]. Using elevators can be challenging for people with dementia [48]. People with dementia may be confused when using elevators and have difficulty understanding the right commands. They can also experience issues with recogniz- 
ing the floor to get out of the elevator and show a certain level of nervousness while using elevators [48]. In Table 1, this is classified as cognitive limitation and as Applying knowledge on the block of predominant activities and Solving problems and Making decisions categories.

Opening doors as ICF block Carrying, moving and handling objects and Lifting and carrying objects/Fine hand use/Hand and arm use as categories are related to visual, mobility and upper extremity limitations. Understanding how to use opening devices is reported as an issue for some blind persons [31], and people with upper extremity impairments can experience difficulties turning door knobs (grasping, releasing, manipulating) or pushing and pulling heavy doors (manipulating) $[5,6,32]$. The ICF block Walking and moving and Walking/Moving around in different locations as categories refer to going through a door, which means crossing door saddles and keeping the door open while manoeuvring walking services $[5$, 6].

No data was found on limited ability to sense smoke, although smoke is one of the key signatures that can help to detect a fire $[9,39]$. The impact of smoke on movement and behaviour has been investigated in the literature [16, 17, 29, 54, 60], but no dedicated studies were found. In Table 1, the evacuation activity Smelling emergency cues predominant activity Purposeful sensory experiences is the block assigned, and Other purposeful sensing as category. The lack of data on impairments causing difficulties in performance of this activity is marked as a research gap connected to other impairments.

The least explored limitation is the role of cognitive impairments due to the demanding design of experiments involving people with these impairments as well as ethical issues. A limited body of experimental research related to cognitive limitations (with a low number of participants in the reviewed experiments) has been found $[48,50]$, and these studies are often very general, as they do not address specific types of cognitive impairments [4-7]. Furthermore, the impact of cognitive impairments on Communication with others/rescue services or similar activity involving understanding of information, processing and replying has not been examined, but it can be crucial in different emergency scenarios [1].

Communication is usually first associated with speaking, but no data was found connecting any kind of speech impairment to evacuation performance in fire scenarios. It would certainly affect the Communication with others/rescue services activity and should be considered and researched in order to provide effective solutions for people with speech impairments. In Table 1, this impairment is marked as research gap classified as other impairments.

The evacuation activity Finding architectural elements as guidance through evacuation routes is discussed in the body of literature in terms of visual limitations (see Table 1) but could also be seen as challenging for people with upper extremities limitation (e.g. not being able to grasp the handrail of stairs or another element in order to navigate themselves or hold on to it during the evacuation). However, dedicated research on this evacuation activity-impairment scenario was not found. 


\section{Discussion}

There have been a few attempts in recent years to meet the needs of people with functional limitations in evacuation scenarios. They have included the pre-evacuation and movement phases, assisted evacuation and self-evacuation, as well as the relationship between reception, perception and realisation of evacuation tasks [8, 20]. Nevertheless, a universal classification of functional limitations in the context of fire safety and evacuation has not yet been made. Following a review of existing literature, this paper presents a detailed categorization of six functional limitations based on a state-of-the-art method adopted in health sciences and accessibility research. Using ICF, the functional limitations were linked to predominant activities during the evacuation phases.

This work allowed the identification of a set of issues. First of all, it is important to distinguish the needs of people with different types of mobility impairments, i.e. those that have the limitations of upper extremities and those with limitations in lower extremities. People who have difficulties in activities such as grasping, holding and pushing, might have problems when interacting with egress components in certain facilities. Limitations in lower extremities, referred to as mobility impairments in the current study, refers to people with reduced spine or lower extremity function, wheelchair users and people walking with mobility devices such as sticks, rollators, etc. This classification is deemed to better inform designers in assessing the needs of these two groups, as these functional limitations are associated with different evacuation activities. The review also highlighted a set of functional limitations that has not been largely investigated. For instance, despite knowing that the ability to smell smoke is a cue in fire emergency scenarios [38], no research has been found related to this functional limitation. Despite the fact that speaking is one of the main means of communication, there are no dedicated studies investigating how speech impairments affect evacuation performance (e.g. communication with rescue services or other occupants). Similarly, given the great variety of conditions and disorders causing cognitive impairments, which may impact the ability to get orientated and communicate with others, limited research has been found on this issue [31].

Although the role of mobility impairments on evacuation activities is the most investigated issue (e.g. activities Using stairs, Getting out of bed, Moving to wheelchair, Moving to escape mattress, etc.), a better understanding of the needs of people with different levels of functional capacity would require the study of a larger variety of specific mobility impairments. While both engineering and medical research address limitations of stamina, [2, 18, 63, 66, 67, 69, 70] and difficulty in reaching with arms and stretching [4, 21, 66, 67], data concerning limitations linked to poor balance, lack of coordination, difficulties in moving head, difficulty in bending, kneeling, etc., loss of upper extremity skills [67] are found only in medical studies. Dedicated fire safety engineering research should consider mobility impairments at a more detailed level linked to different evacuation activities.

The interaction between groups with functional limitations and the environment can be perceived as an existing barrier for every evacuation activity [75], which represents the static dimension of this relationship. For example, in the literature, 
the ability of people with functional limitations to negotiate doors, i.e. turn the door knob, cross door saddle, keep the door opened has been analysed [6] but with limited sample sizes, which may not be considered representative of the great variety of actual limitations affecting this evacuation activity. Turning the door knob, crossing door saddle, keeping the door opened are the environmental barriers for the evacuation activity Opening doors (see Table 1). The level of activity performance depends on the interaction between the person with functional limitations and the specific environmental demands, i.e. if the environmental demands become barriers or the individuals manage to deal with them. The importance of including the concept of barriers in future research is also reflected in addressing the variety and complexity of functional limitations. For the activity Opening doors, in relation to the barrier turn the door knob, the third level of ICF can be assigned, e.g. Grasping for the ICF category Fine hand use, and Pulling or Pushing for Hand and arm use. This way, the barriers help perceiving certain activity performance linked to specific functional limitation on even more detailed level, which can help better understanding the needs of vulnerable groups.

Depending on the degree of mobility loss, people with mobility limitations may need to use assistive devices for evacuation. Different studies (evacuation drills, experiments, egressibility studies) have been conducted on the types of assistive devices for assisted and non-assisted evacuation [4, 21, 24, 28, 36, 37, 42, 45, 65]. These studies provide data about the amount of time needed to prepare assistance, velocities of the assistive devices, total evacuation time depending on the type of device, their size and weight, physical demands on supporters and optimal number of people to manage devices during the evacuation. However, there are limited data on the activities that people with functional limitations need to perform to prepare for this type of evacuation. They will differ on several factors such as whether the evacuation is assisted or not (e.g. the activities getting out of bed and moving to a wheelchair are harder to perform without assistance) or the experience of the person(s) giving assistance [12], causing frequent delays in the evacuation [51]. Additionally, the type of functional limitations will affect the activity performance and the type of assistive device that is most efficient for a given impairment. Further research should therefore be conducted to investigate the relationship between these variables.

Besides the static analysis of the evacuation activities in relation to functional limitations conducted in the present work, future research should include dynamic analyses to account for the variability present in different emergency egress situations. This could include the time required to go through an egress component, or interpret and use a means of escape. For example, in contrast to the accessibility domain, during an evacuation, conditions affecting the accessibility of the means of egress may vary substantially over time both in terms of the population (e.g. using medications, substance abuse, assisted vs. self-evacuation) as well as the environment (e.g. lighting, presence of smoke/heat) [14, 57]. In particular, substance/medication use has been scarcely investigated in terms of its impact on evacuation, even though the impact of substances has been identified as an issue in the evacuation domain [3, 59]. This is also an issue because groups of older people with functional limitations making use of medication are a high risk group 
in fire scenarios [64]. In this context, we believe that the ICF can facilitate the evaluation in dynamic conditions and expand the knowledge on the subject.

Another issue identified is that most studies look at the impact of a given impairment in isolation. In contrast, people may have multiple impairments, and public buildings can often be very crowded, thus adding another layer of complexity to the specific evacuation needs of people with functional limitations. In crowded places, the evacuation performance of heterogeneous groups, including people with several functional limitations and able-bodied populations, will highly depend on the interactions between these groups and the space they are surrounded by $[14,19,22]$. In a study on the movement of heterogeneous groups trough bottlenecks, it is shown that the higher mixing ratios of wheelchair users and pedestrians affect the moving efficiency and increase congestion. The degree of this impact is also depending on the design (i.e. the angle) of the bottleneck [46]. In general, the underlying dynamics of social groups can indeed have a significant impact in emergency scenarios [44, 73].

This study indicated a scarcity of information on the role of cognitive impairments on evacuation activities. This was expected given the difficulties in collecting such data due to ethical and practical constraints. Therefore, the suggested classification has a limited application in this domain. While the evacuation activities and functional limitations listed in Table 1 are extracted from the literature, future research could focus on predicting the activities which are potentially harder to perform and which may have a greater impact on evacuation performance. This can depend on the nature of the population and the environment. Thus, future research should aim to develop an egressibility scale able to categorize and rank the spaces from an egress standpoint in relation to the specific population under consideration. Taking a further step in this research direction would involve developing a list of barriers for every evacuation activity, so that the functional limitations - the negative aspects of the interaction between an individual (their health condition) and the environment - can be analysed in-depth in a given space.

\section{Conclusion}

This paper introduces the use of ICF to identify predominant activities during an evacuation. In addition, six groups of functional limitations have been listed and linked to the evacuation activities included in the evacuation time-line. The suggested classification can facilitate the assessment of evacuation-related issues in buildings in relation to functional limitations of the population under consideration. The main research gaps identified include the lack of studies concerning the role of cognitive limitations during egress, and the need to combine the dynamic issues that characterize the temporal dimension of an evacuation scenario to allow for the use of methods from accessibility research in the field of egress. This effort is deemed to provide a useful starting point for fire safety engineers designing public spaces. The end goal of this work is to provide the basis for the safety 
assessment of buildings that considers the whole spectrum of functional limitations which may be present in a population.

\section{Funding}

Open access funding provided by Lund University. Funding was provided by Svenska Forskningsrådet Formas (Grant No. 2018-00575). This study was conducted within the context of the Centre for Ageing and Supportive Environments (CASE) at Lund University. Olivera Bukvic has been awarded the International Credit Mobility Grant within the framework of the Erasmus + Programme as a visiting PhD student at Lund University.

\section{Open Access}

This article is licensed under a Creative Commons Attribution 4.0 International License, which permits use, sharing, adaptation, distribution and reproduction in any medium or format, as long as you give appropriate credit to the original author(s) and the source, provide a link to the Creative Commons licence, and indicate if changes were made. The images or other third party material in this article are included in the article's Creative Commons licence, unless indicated otherwise in a credit line to the material. If material is not included in the article's Creative Commons licence and your intended use is not permitted by statutory regulation or exceeds the permitted use, you will need to obtain permission directly from the copyright holder. To view a copy of this licence, visit http://creat ivecommons.org/licenses/by/4.0/.

\section{ELECTRONIC SUPPLEMENTARY MATERIAL}

The online version of this article (https://doi.org/10.1007/s10694-020-01034-5) contains supplementary material, which is available to authorized users.

\section{References}

1. Arias S, Fahy R, Ronchi E, Nilsson D, Frantzich H, Wahlqvist J (2019) Forensic virtual reality: investigating individual behavior in the MGM grand fire. Fire Saf $\mathbf{J}$ 109:102861

2. Averill JD, Dennis SM, Peacock RD, Kuligowski ED, Groner N, Proulx G, Nelson HE (2005) Collapse of the world trade center tower. National Institute of Standards and Technology

3. Björkqvist M, Agnes FB (2018) Människors benägenhet till utrymning vid alkoholpåverkan. Lund University, Report 5553, Lund, Sweden

4. Boyce KE, Shields TJ, Silcock GWH (1999) Toward the characterization of building occupancies for fire safety engineering: capability of people with disabilities to read and locate exit signs. Fire Technol 35(1):79-86 
5. Boyce KE, Shields TJ, Silcock GWH (1999) Toward the characterization of building occupancies for fire safety: prevalence, type, and mobility of disabled people. Fire Technol 35(1):35-50

6. Boyce KE, Shields TJ, Silcock GWH, Sert F (1999) Toward the characterization of building occupancies for fire safe engineering: capability of disabled people to negotiate doors. Fire Technol 35(1):68-78

7. Boyce KE, Shields TJ, Silcock GWH, Sert F (1999) Toward the characterization of building occupancies for fire safety engineering: capabilities of disabled people moving horizontally and on an incline. Fire Technol 35(1):51-67

8. Boyce K (2017) Safe evacuation for all - fact or fantasy? past experiences, current understanding and future challenges. Fire Saf J 91:28-40

9. Burian B (2005) Do you smell smoke? Issues in the design and content of checklists for smoke, fire, and fumes. In: Proceeding of the international society of air safety investigators 2005 conference. National Aeronautics and Space Administration, Human System Integration Division, Forth Worth, Texas

10. Butler K, Kuligowski E, Furman S, Peacock R (2017) Perspectives of occupants with mobility impairments on evacuation methods for use during fire emergencies. Fire Saf $\mathbf{J}$ 91:955-963

11. Carattin E, Ruggiero L, Enrico R, Daniel N (2016) Affordance-based evaluation of signage design for areas of refuge. In: 14th international conference and exhibition on fire science and engineering. Interscience Communications, Royal Holloway College, University of London, UK

12. Catovic L, Alniemi C, Ronchi E (2018) A survey on the factors affecting horizontal assisted evacuation in hospitals. J Phys: Conf Ser. 1107(7):072001. https://doi.org/ 10.1088/1742-6596/1107/7/072001

13. Christensen KM, Collins SD, Holt JM, Phillips CN (2014) The relationship between the design of the built environment and the ability to egress of individuals with disabilities. Rev Disabil Stud Int J 2(3)

14. Feliciani C, Murakami H, Shimura K, Nishinari K (2020) Efficiently informing crowds - experiments and simulations on route choice and decision making in pedestrian crowds with wheelchair users. Transp Res Part C Emerg Technol 114:484-503

15. Fernández-Vigil M, Echeverría Trueba B (2019) Elderly at Home: A Case for the Systematic Collection and Analysis of Fire Statistics in Spain. Fire Technol 55(6):22152244

16. Fridolf K, Andrée K, Nilsson D, Frantzich H (2014) The impact of smoke on walking speed. Fire Mater 38(7):744-759

17. Fridolf K, Ronchi E, Nilsson D, Frantzich H (2013) Movement speed and exit choice in smoke-filled rail tunnels. Fire Saf J 59:8-21

18. Galea ER, Hulse L, Day R, Siddiqui A, Sharp G (2009) The UK WTC 9/11 evacuation study: an overview of the methodologies employed and some analysis relating to fatigue, stair travel speeds and occupant response times. In: Proceedings of the 4th international symposium on human behaviour in fire. Robinson College, Cambridge, UK, pp $27-40$

19. Geoerg P, Florian B, Steven G, Karen B, Stefan H, Anja H (2019) Engineering egress data considering pedestrians with reduced mobility. Fire Mater 43(7):759-781

20. Geoerg P, Block R, Heister W, Holl S, Pulm A, Hofmann A (2017) A score regarding the need for assistance - considering pedestrians with impairments in evacuation planning. In: Proceedings of the 5th Magdeburger Fire and Explosion Prevention Day 
21. Geoerg P, Polzin RM, Schumann J, Holl S, Hofmann A (2018) Small-scale studies on evacuation characteristics of pedestrians with physical, mental or age-related disabilities. J Phys: Conf Ser 1107:072006

22. Geoerg P, Schumann J, Holl S, Hofmann A (2019) The influence of wheelchair users on movement in a bottleneck and a corridor. J Adv Transp 2019:1-17

23. Gwynne SMV, Boyce KE (2016) Engineering data. In: Hurley MJ, Gottuk DT, Hall JR, Harada K, Kuligowski ED, Puchovsky M, Torero JL, Watts JM, Wieczorek CJ (eds) SFPE handbook of fire protection engineering, Springer, New York, pp 24292551

24. Hashemi M (2018) Dynamic, stream-balancing, turn-minimizing, accessible wayfinding for emergency evacuation of people who use a wheelchair. Fire Technol 54(5):11951217

25. Hashemi M (2018) Emergency evacuation of people with disabilities: a survey of drills, simulations, and accessibility' edited by S Tomasiello. Cogent Eng 5(1):1506304

26. Hedman GE (2011) Travel along stairs by individuals with disabilities: a summary of devices used during routine travel and travel during emergencies. In: Peacock RD, Kuligowski ED, Averill JD (eds) Pedestrian and evacuation dynamics. Springer, Boston, MA, pp 109-19

27. Huey RW, Buckley DS, Lerner ND (1996) Audible performance of smoke alarm sounds. Int J Ind Ergon 18(1):61-69

28. Hunt A, Galea ER, Lawrence PJ (2015) An analysis and numerical simulation of the performance of trained hospital staff using movement assist devices to evacuate people with reduced mobility: movement assist devices to evacuate PRM. Fire Mater 39(4):407-429

29. Jin T (2008) Visibility and human behavior in fire smoke. In: SFPE handbook of fire protection engineering, 3rd ed. National Fire Protection Association, Quincy, MA, pp 2-42-2-53

30. Jonsson A, Runefors M, Särdqvist S, Nilson F (2016) Fire-related mortality in Sweden: temporal trends 1952 to 2013. Fire Technol 52(6):1697-1707

31. Kecklund L, Andrée K, Bengston S, Willander S, Siré E (2012) How do people with disabilities consider fire safety and evacuation possibilities in historical buildings?-A Swedish case study. Fire Technol 48(1):27-41

32. Kesler RM, Klieger AE, Boes MK, Hsiao-Wecksler ET, Klaren RE, Learmonth Y, Motl RW, Horn GP (2017) Egress efficacy of persons with multiple sclerosis during simulated evacuations. Fire Technol 53(6):2007-2021

33. Kuklane K, Ingvar H (2002) Respiratory flow patterns during physical work with respirators. Arbetslivsinstitutet

34. Kuligowski ED (2016) Human behavior in fire. In: Hurley MJ, Gottuk D, Hall JR, Harada K, Kuligowski E, Puchovsky M, Torero J, Watts JM, Wieczorek C (eds) SFPE handbook of fire protection engineering, Springer, New York, pp 2070-2114

35. Kuligowski E, Peacock R, Wiess E, Hoskins B (2013) Stair evacuation of older adults and people with mobility impairments. Fire Saf J 62:230-237

36. Lavender SA, Hedman GE, Mehta JP, Reichelt PA, Conrad KM, Park S (2014) Evaluating the physical demands on firefighters using hand-carried stair descent devices to evacuate mobility-limited occupants from high-rise buildings. Appl Ergonom 45(3):389397

37. Lavender SA, Mehta JP, Hedman GE, Park S, Reichelt PA, Conrad KM (2015) Evaluating the physical demands when using sled-type stair descent devices to evacuate mobility-limited occupants from high-rise buildings. Appl Ergonom 50:87-97 
38. Lloyd M, Roen K (2002) "When you smell smoke...": "risk factors" and fire safety in action. HealthRisk Soc 4(2):139-153

39. Lloyd M, Roen K (2002) "When you smell smoke...": 'risk factors' and fire safety in action. Health Risk Soc 4(2):139-153

40. McConnell NC, Boyce KE (2015) Refuge areas and vertical evacuation of multistorey buildings: the end users perspectives. Fire Mater 39(4):396-406

41. Meacham BJ (1997) An introduction to performance-based fire safety analysis and design with applications to structural fire safety. In: Building to last. ASCE, pp. 529533

42. Mehta JP, Lavender SA, Hedman GE, Reichelt PA, Park S, Conrad KM (2015) Evaluating the physical demands on firefighters using track-type stair descent devices to evacuate mobility-limited occupants from high-rise buildings. Appl Ergonom 46:96-106

43. Moinuddin KAM, Bruck D, Shi L (2017) An experimental study on timely activation of smoke alarms and their effective notification in typical residential buildings. Fire Saf J 93:1-11

44. Moussaïd M, Trauernicht M (2016) Patterns of cooperation during collective emergencies in the help-or-escape social dilemma. Sci Rep 6:33417

45. Ohtsu N, Hokugo A (2019) Velocity and transportation ability of vulnerable people during a community tsunami evacuation drill: outdoor evacuation using a rollator, transport chair, wheelchair, and cart in Shinyo Bokomi, Kobe, Japan. Jpn Architect Rev 2(4):576-587

46. Pan H, Zhang J, Song W (2020) Experimental study of pedestrian flow mixed with wheelchair users through funnel-shaped bottlenecks. J Stat Mech Theory Exp 2020(3):033401

47. Park E-S, Yoon DK, Choi Y-W (2019) Leave no one behind: experiences of persons with disability after the 2017 Pohang Earthquake in South Korea. Int J Disast Risk Reduct 40:101261

48. Passini R, Pigot H, Rainville C, Tétreault M-H (2000) Wayfinding in a nursing home for advanced dementia of the alzheimer's type. Environ Behav 32(5):684-710

49. Passini R, Proulx G (1988) Wayfinding without vision: an experiment with congenitally totally blind people. Environ Behav 20(2):227-252

50. Passini R, Rainville C, Marchand N, Joanette Y (1995) Wayfinding in dementia of the alzheimer type: planning abilities. J Clin Exp Neuropsychol 17(6):820-832

51. Proulx G (2003) Recollection, identification and perceived urgency of the temporalthree evacuation signal. J Fire Prot Eng 13(1):67-82

52. Proulx G (1995) Evacuation time and movement in apartment buildings. Fire Saf $\mathbf{J}$ 24(3):229-246

53. Proulx G (2002) Evacuation planning for occupants with disability. Fire Risk Management Program, Institute for Research in Construction

54. Proulx G, Fahy RF (2008) Human behavior and evacuation movement in smoke. ASHRAE Trans 114(2):159-165

55. Proulx G, Kyle B, Creak J (2000) Effectiveness of a photoluminescent wayguidance system. Fire Technol 36(4):236-248

56. Purser DA, Bensilum M (2001) Quantification of behaviour for engineering design standards and escape time calculations. Saf Sci 38(2):157-182

57. Purser DA (2008) Assessment of hazards to occupants from smoke, toxic gases and heat. In: SFPE handbook of fire protection engineering, 4th edn. Di Nenno P. J, Quincy, MA

58. Roberts JL (2005) An area of refuge: due process analysis and emergency evacuation for people with disabilities. Va J Soc Policy Law 13:127-178 
59. Ronchi E, Nieto Uriz F, Criel X, Reilly P (2016) Modelling large-scale evacuation of music festivals. Case Stud Fire Saf 5:11-19

60. Ronchi E, Fridolf K, Frantzich H, Nilsson D, Walter AL, Modig H (2018) A tunnel evacuation experiment on movement speed and exit choice in smoke. Fire Saf J 97:126136

61. Ronchi E, Nilsson D (2013) Fire evacuation in high-rise buildings: a review of human behaviour and modelling research. Fire Sci Rev 2(1):7

62. Ronchi E, Daniel N (2016) Basic concepts and modelling methods. In: Cuesta A, Abreu O, Alvear D (eds) Evacuation modeling trends, Springer International Publishing, Cham

63. Ronchi E, Johan N, Mattias D, Kalev K, Amitava H, Silvia A, Karl F (2015) Ascending evacuation in long stairways: physical exertion, walking speed and behaviour. Department of Fire Safety Engineering, Lund University, Lund, Sweden

64. Runefors M, Johansson N, Van Hees P (2016) How could the fire fatalities have been prevented? An analysis of 144 cases during 2011-2014 in Sweden: an analysis. J Fire Sci 34(6):515-527

65. Schumann J, Maik B (2017) Tracking of wheelchair users in dense crowds. In: International conference on indoor positioning and indoor navigation

66. Slaug B, Schilling O, Iwarsson S, Carlsson G (2011) Defining profiles of functional limitations in groups of older persons: how and why?. J Aging Health 23(3):578-604

67. Slaug B, Schilling O, Iwarsson S, Carlsson G (2015) Typology of person-environment fit constellations: a platform addressing accessibility problems in the built environment for people with functional limitations. BMC Public Health 15(1):834

68. Sørensen JG, Danmarks TU, DTU Byg (2015) Evacuation of people with visual impairments. PhD Thesis. DTU Civil Engineering, Technical University of Denmark, Lyngby

69. Spearpoint M, MacLennan HA (2012) The effect of an ageing and less fit population on the ability of people to egress buildings. Saf Sci 50(8):1675-1684

70. Stewart A, Elyan E, Isaacs J, McEwen L, Wilson L (2017) The effect of person order on egress time: a simulation model of evacuation from a neolithic visitor attraction. Hum Fact J Hum Fact Ergonom Soc 59(8):1222-1232

71. Thompson P, Nilsson D, Boyce K, McGrath D (2015) Evacuation models are running out of time. Fire Saf J 78:251-261

72. Verbrugge LM, Jette AM (1994) The disablement process. Sm Sci Med 38(1):1-14

73. Warren WH (2018) Collective motion in human crowds. Curr Dir Psychol Sci 27(4):232-240

74. Wickramasinghe A, Ranasinghe DC, Fumeaux C, Hill KD, Visvanathan R (2017) Sequence learning with passive RFID sensors for real-time bed-egress recognition in older people. IEEE J Biomed Health Informat 21(4):917-929

75. World Health Organization (ed) (2001) International classification of functioning, disability and health: ICF. World Health Organization, Geneva 